\title{
Let's Reclaim Our Food Sovereignty and Reject the Industrial Food System!
}

\author{
Nora McKeon ${ }^{1}$ \\ Published online: 8 November 2021 \\ (c) Society for International Development 2021
}

\begin{abstract}
African food systems are a rich and varied tapestry of production systems, crops, seed, territorial markets, cultures, biodiversity and ecologies. As the UN Food Systems Summit worked to retrench the many pathologies that have systematically eroded African food systems, African civil society organizations mobilized to push back. In the African regional people's countermobilization, participatory dialogues opened space for continent-wide articulations of a future built on peoples' choices and control of natural resources, territorially-embedded solutions, the human rights of all, family farming, and peasant agroecology.
\end{abstract}

Keywords Africa · Family farming · Food sovereignty $\cdot$ UN Food Systems Summit · Extractivism · Power

'Let's Reclaim our Food Sovereignty and Reject the Industrial Food System!' is the overall headline of the common position adopted by African small-scale producer and civil society organizations in the run-up to the UN Food Systems Summit (UNFSS). It reflects both a strong denunciation of corporate capture of African resources, markets, and knowledge, coming from the ground across the continent, and a convergence around the vision of African food systems that the signatories are defending.

The declaration ${ }^{1}$ was presented at a well-attended virtual conference held in July 2021 in the context of the People's Counter-Mobilization to Transform Corporate Food Systems. ${ }^{2}$ It was prepared by an innovative platform of African networks that cut across colonial language, sectoral and

The article in based on the proceedings of the African regional people's counter mobilization to transform corporate food systems and benefitted from an extensive interview with the African Centre for Biodiversity.

Nora McKeon

nora.mckeon@fastwebnet.it

1 International University College of Turin and Roma Tre University, Rome, Italy geographic divides. Small-scale producers of different kinds were explicitly on the frontline in developing the contents of the declarations, ${ }^{3}$ along with Indigenous Peoples and the urban food insecure. ${ }^{4}$ They were backed by broad intersectoral networks and civil society think tanks ${ }^{5}$ with their analytical and communications capacity. The modalities applied were inspired by those of the Civil Society and Indigenous Peoples' Mechanism (CSM) that interfaces with the UN Committee on World Food Security (CFS). These ensure that privileged voice is granted to organizations representing those who suffer most from food insecurity and, at the same time, produce most of the food consumed in the world. Like the CSM, the platform was conceived not as some sort of super-organization or network of networks, but as a space

\footnotetext{
1 https://www.foodsystems4people.org/africa-responds-to-the-unfood-systems-summit/ accessed 10 October 2021.

2 https://www.csm4cfs.org/call-action-mobilization-challenge-unfood-systems-summit-re-claim-peoples-sovereignty-food-systems/ accessed 10 October 2021.

3 The peasants and family farmers of the Network of Farmers Organizations and Agricultural Producers of West Africa (ROPPA), La Via Campesina and Plateforme Régionale des Organisations Paysannes d'Afrique Centrale (PROPAC), the fisherfolk of World Forum of Fish Harvesters and Fish Workers (WFF) and World Forum of Fisher Peoples (WFFP), pastoralists from the World Alliance of Mobile Indigenous Peoples (WAMIP).

4 Habitat International Coalition (HIC).

5 Alliance for Food Sovereignty in Africa and Slow Food, African Centre for Biodiversity, BioWatch.
} 
in which different actors could share information and analysis and collectively build their political understanding and strengthen their positioning.

The drafting work was conducted collegially and patiently. As it evolved, it constituted an occasion to appreciate the diversity of experiences of different constituencies and ecosystems while identifying the common challenges they all face. As the opening sentences of the declaration acknowledge: 'African food systems are a rich and varied tapestry of production systems, crops, seeds, territorial markets, cultures, biodiversity and ecologies. However, many of these systems have been weakened and systematically eroded by decades of state neglect, governance failure, public underinvestment, economic and political subordination, and corporate capture'. The points put forward by all of the constituencies found their place in the collective statement in a practical exercise of building convergence among different actors starting from different issues in different spaces.

The drafters and signatories of the declaration are very well aware that Africa is the prime target of the intensified, multifaceted extractivism that the UNFSS is designed to propel through 'a wider agenda, which is about deepening extraction from the continent-of labour, minerals, wood, water, food, fibre, genetic material and finance. This is being done to feed the desires of the world's wealthy consumers and the profits of corporations, but is being framed as a development pathway for Africa'. For this very reason, an African civil society push-back is not only in the interests of the continent. 'We hold that there is an inextricable interconnectedness between climate change, deforestation and ocean degradation, industrial food production and, generally speaking, agrarian extractivism and extractivist development... and the systemic, existential crises we face globally. We stand by our common position in defense not only of African people and territories, but of the world at large.'

The vision defended in the declaration, which has been underwritten by 127 organizations, is one of food sovereignty, built on peoples' choices and control of natural resources, territorially-embedded solutions, the human rights of all, family farming, and peasant agroecology. The latter is far more than a collection of practices. It involves peoples' entire life systems and so cannot simply be inserted into contexts of authoritarian governance and conflict but demands broad and radical transformation. The outcomes expected from the realization of this vision include protection and strengthening of healthy ecosystems and biodiversity and the solidarity and wellbeing of indigenous and local communities. It is understood that this cannot begin to happen without the full participation of the population in decision-making, particularly the most marginalized sectors, and the primacy of public policies over privatization. The 'vision' section was deliberately placed first in the declaration, before the denunciation of corporate control and the
UNFSS, in order to break with an agency-paralyzing concentration on what's going wrong.

Throughout the drafting of the declaration an effort was made to ground it in the experiences of communities and make it resonate with their concerns, which were very far from preoccupations about the holding of an unimaginably remote global Food Systems Summit. One member of the drafting group dropped out for a period while her town in South Africa was overwhelmed by a desperation-fueled insurrection. Another was holed up in her house in Cameroon by a lock-down occasioned not only by COVID-19 but also by terrorist activity sparked by the same motivations. The pastoralist participant speaking from Northern Mali was almost inevitably without internet connection, while the defender of urban food insecure in Uganda could not connect after he had to leave his office to respect the 5 pm curfew. How to start from the conditions that people are living and build a collective understanding of their structural causes and a collective determination to transform them? This was the ambitious but essential long-term objective to which the group wished to contribute.

The declaration is very firmly directed towards African authorities. While acknowledging that regulation of corporations and financial speculators faces strong opposition from the powerful actors that dominate markets, the signatories 'hold our governments to account for failing to put in place adequate fiscal policies and regulations to protect Africa's food sovereignty'. This is an extremely important stance. It is easy, and understandable, to put the blame for Africa's woes on the powerful external actors who have played such a decisive hand in shaping its situation since the time of overt colonialism. But this is not the route to transformation. The declaration's signatories address their recommendations squarely to African governments and the African Union, followed by a reminder to the UN and its agencies to defend their dedication to human rights and to African civil society itself, whose mobilization is required to make the rest happen.

This determination to call African authorities to account was reinforced shortly after the July 2021 virtual conference, when the regional coordination group obtained a leaked copy of the draft 'African Common Position to the UN Food Systems Summit' that the AU was preparing for submission to the UNFSS. When requests that this draft be made public and opened up for discussion were refused, the group reacted with a second declaration that was presented to another well-attended regional conference on 16 September. ${ }^{6}$ There was nothing 'common' about the AU position,

\footnotetext{
${ }^{6}$ African social movements rise-up against the UNFSS and the AU's blueprint for corporate capture of our food systems, online meeting, 16 September 2021: https://bit.ly/2WY993C accessed 10 October 2021.
} 
the African social movements and civil society organizations maintained, either in its content or in its process. Although the AU text claimed that it was based on an 'inclusive' process of country and regional dialogues which incorporated a 'diversity of voices from the grassroots', the signatories 'vehemently challenge' this false narrative of a 'People's Summit' by pointing out that the majority of the national dialogues organized in the context of the UNFSS were hastily put together, with no effort to include the wide range of constituencies. In some countries where there is a strong peasant movement, their platforms were involved in the national level dialogues, but the concerns they expressed are not reflected in the $\mathrm{AU}$ 'Common Position'.

So, the declaration asks rhetorically, "who decides what goes into an AU Common Position and what stays out?' The lack of transparency of the African Union and its susceptibility to co-optation, given the lack of a structure of democratic accountability mounting upwards from the base, is a key issue. The African people's declaration notes, in fact, that the AU machinery is currently churning out a series of continental policies that promote large-scale, private-sector driven 'improved' seed and genetic engineering, bio and industrial food fortification, 'blue growth' initiatives and digitalization although a good number of African member governments are not aligned with these approaches and, indeed, have supported others in the context of initiatives such as the UN's Declaration on the Rights of Peasants and other People Working in Rural Areas (UNDROP).

Content-wise, the declaration states, the draft AU position 'fails to consider critically key drivers for the current crises. Corporate power, the pillaging of the public purse through systemic and endemic corruption, the human, economic and environmental devastation caused by ongoing and new armed conflicts, and the role that extractivist development plays in fomenting such destruction are worryingly absent from the AU's analysis'. The AU document views regional and global integration and the promotion of large-scale farming as central to food systems transformation, ignoring the evidence that the confluence of financialization and large-scale land investments have and will continue to result in land and resource grabbing from communities. It is silent on agroecology, despite the centrality of this alternative to industrial food production in the practice and narratives of the millions of small-scale producers who form the basis of Africa's food systems, and its pertinence in the context of the climate crisis. The single paragraph of the 19- page document that discusses COVID-19-the overwhelming priority challenge that Africa's people are facing-is totally silent on making meaningful recommendations to address it, suggesting instead that digital solutions and innovative financing through public-private partnerships could be considered.

In the end, the intervention in the opening session of the UNFSS of the Chairperson of the AU, the President of the Democratic Republic of the Congo Félix-Antoine Tshisekedi, made no reference to the AU 'common position'. At the time of writing, the intervention did not seem to have been posted on the UNFSS website, although the intricate unfathomableness of this instrument makes it difficult to be certain. Whether or not the African social movements and civil society's position helped to push the AU draft off the table is not known, but it is certain that the battle continues. The African Union is currently pushing the hasty finalization of important continental guidelines for seed harmonization and biotechnology with a seriously inadequate process of consultation of those most affected. The guidelines point in the direction of formalizing, standardizing, and industrializing the African food system, to the benefit of corporate interests and against those of the small-scale producers and food insecure urban consumers who are the vast majority of the population, as clearly set out in a letter addressed to AU authorities in late August 2021. ${ }^{7}$ Also just around the corner is the African Union-European Union Summit which is expected to ratify a 'partnership' crafted around European Green Deal and trade agendas, involving little consultation with European civil society organizations and none at all on the African side.

The September 2021 conference of the African people's countermobilization closed with strong call on the African Union to establish an open, transparent dialogue on the range of continental food-related policies and agreements. The challenge is enormous, nothing less than building democracy and people's sovereignty from the base upwards and outwards. The African people's regional counter mobilization, given the vision and energy it has generated, is perfectly placed to provide a critical contribution to such a fundamental struggle.

Publisher's Note Springer Nature remains neutral with regard to jurisdictional claims in published maps and institutional affiliations.

\footnotetext{
${ }^{7}$ https://www.acbio.org.za/guidelines-harmonisation-seed-regul atory-frameworks-africa-call-african-social-movements-block, accessed 10 October 2021.
} 